Original Article

\title{
ANTIOXIDANT AND TYROSINASE INHIBITORY PROPERTIES OF AQUEOUS ETHANOL EXTRACTS FROM MONOFLORAL BEE POLLEN
}

\author{
Hongcheng Zhang ${ }^{1 *}$ \\ Xue Wang ${ }^{1}$ \\ Kai Wang ${ }^{1}$ \\ Chunyang $\mathrm{Li}^{2}$ \\ ${ }^{1}$ Institute of Apicultural Research, Chinese Academy of Agricultural Sciences, \\ No. 1, Beigou, Xiangshan, 100093 Beijng, China \\ 2 Institute of Agricultural Products Processing, Jiangsu Academy of Agricultural Sciences, \\ No.50 Zhongling Street, Nanjing, Jiangsu 210014, China \\ *corresponding author: 460414874@qq.com \\ Received 13 February 2015; accepted 15 May 2015
}

\begin{abstract}
Bee pollen has been used for many years in traditional medicine and supplementary nutrients. Bee pollen is mainly composed of nutrients and bioactive substances which might act as potential antioxidants and tyrosinase inhibitors. In this study, 14 species of monofloral bee pollen from China were collected to analyse their antioxidant and tyrosinase inhibitory properties. Our results revealed that virtually all the bee pollen samples possessed powerful antioxidant or tyrosinase inhibitory activities. These properties varied greatly depending on the floral species and extraction solvents. To extract phenolics of various species of bee pollen, the most effective solvent may be a solvent which is a 75 wt. \% ethanol/water. Extracts of wuweizi, rape, phellodendron, apricot, and dandelion pollen had stronger antioxidant activities; on the other hand, those of apricot, camellia, and sunflower presented excellent tyrosinase inhibitory activities. In addition, we may have found a novel discovery: that apricot pollen exhibits both powerful antioxidant and strong tyrosinase inhibitory activities.
\end{abstract}

Keywords: antioxidant activities, aqueous ethanol extracts, bee pollen, tyrosinase inhibitory activities.

\section{INTRODUCTION}

Pollen is a fine powder-like material. It is the male reproductive cells of phanerogam. Bee pollen is gathered and combined with plant nectar and bee saliva by worker bees. Then it is compacted into pellets and used as food for honeybees. Bee pollen has also been used for many years in traditional medicine and supplementary nutrients, primarily because bee pollen has nutritional and health benefits. Potential therapeutic benefits include hepatoprotective (Cheng et al., 2013) and antioxidant (Leja et al., 2007) activities. Such uses suggest that bee pollen could be useful in the prevention of diseases associated with free radicals (Pascoal et al., 2014). These therapeutic and protective effects, especially antioxidant activities, may be related to polyphenols.
Antioxidant activities of bee pollen may be associated with the floral species. There is a large variety and wide distribution of bee pollen in China. Its trade volume reached 4500 tons in 2013 . Thus, it appears necessary to determine the antioxidant activities of various species of bee pollen in China, for their further development and utilisation. The antioxidant activities of bee pollen extract are also affected by extraction solvents. Previous studies have demonstrated that extraction solvents have a significant influence on the contents of polyphenols and antioxidant activities (Jaiswal et al., 2012). Such solvents as methanol, ethanol, acetone, ethyl acetate, and their combinations, often with different proportions of water, have been used for the extraction of phenolics from plant materials. Choosing a good solvent for phenolics extraction and one which is safe for humans, is necessary. 
Tyrosinase (monophenol monooxygenase, E:C:1.14. 18.1), known as polyphenol oxidase (PPO), is a copper-containing enzyme. Tyrosinase is widely distributed in plants, animals, and microorganisms. This enzyme catalyses two distinct reactions of melanin synthesis; the hydroxylation of a monophenol, and the conversion of an o-diphenol to the corresponding o-quinone (Tsong-Min, 2012). Quinones with highly reactive compounds can polymerise spontaneously to form melanins. Melanin is the pigment responsible for the colour of human skin and hair. The excessive accumulation of melanin not only affects the colour of the human skin but also leads to dermatological disorders, such as melasma, age spots, and sites of actinic damage (Huang et al., 2014). Tyrosinase inhibitors have received considerable attention for use in cosmetics, especially for skin whitening (Jayanthi and Lalitha, 2014). In China, bee pollen has been used as an anti-aging and whitening cosmetic for centuries. Ancient Chinese used a combination of honey and bee pollen to whiten skin and an oriental anti-aging formula contained bee pollen, honey, and ginseng. Nowadays, there are more than twenty cosmetic products containing bee pollen in China. Some companies recommend that bee pollen from the camellia, sunflower, and lotus can be used for the best skin whitening effect. Crocus sativus pollen was reported to be used as an additive product in whitening cosmetics because of its anti-tyrosinase activity (Li and Wu, 2002). Yet, to our knowledge, few previous studies focused on the tyrosinase inhibitory properties of bee pollen from different botanical origins.

The first aim of this study was to prepare various extracts from 14 species of monofloral bee pollen in China, by means of using different aqueous ethanol solvents. The second aim was to evaluate the antioxidant and tyrosinase inhibitory properties of various bee pollen extracts.

\section{MATERIAL AND METHODS}

\section{Chemicals}

All reagents used in the experiment were of analytical grade. The suppliers of the reagents were: DPPH (1,1-diphenyl-2-picrylhydrazyl), Folin-Ciocalteu's phenol reagent (2 N) and Trolox (6-hydroxy-2,5,7,8tetramethylchroman-2-carboxylic acid), L-tyrosine, L-dopa and tyrosinase from Sigma (St. Louis, MO, USA); ABTS (2,2-azinobis 3-ethylbenzothiozoline-6sulfonic acid) from Fluka Chemie $\mathrm{GmbH}$ (Buchs, Switzerland). Rutin, sodium carbonate, sodium nitrite, aluminium nitrate, sodium hydroxide, disodium hydrogen phosphate, sodium dihydrogen phosphate, and anhydrous ethanol were from Beijing Chemical Co. Ltd (Beijing, China).

\section{Bee Pollen sample}

In this study, 14 species of monofloral bee pollen were obtained from 12 apiaries of the Modern Agroindustry Research System in China. The bee pollen was obtained during the 2013 flowering season (Tab. 1). The identification of the botanical origins, and bee pollen colour were assayed according to the method of Sun (1993). The purity of the pollen samples was found by counting the number of the non-matching types of pollen grains among $2 \mathrm{~g}$ of the pollen sample grains, and calculating the purity (\%) of the bee pollen. Bee pollen particles were dried to a constant weight at $50^{\circ} \mathrm{C}$ in a vacuum-drying oven (DZF-6090, Heng scientific instrument Co., Ltd, Shanghai, China), and then ground into powder. The powdered bee pollen sample was stored at $-18^{\circ} \mathrm{C}$ until needed.

\section{Extraction}

A powdered bee pollen sample of $5 \mathrm{~g}$ was successively mixed $(1: 20, w / v)$ with $0,25,50,75$, and 100 wt. \% ethanol/water solvents. After extraction for $24 \mathrm{~h}$ at room temperature, the mixtures were respectively centrifuged at $2000 \times \mathrm{g}$ for $10 \mathrm{~min}$. The supernatants were diluted to $100 \mathrm{~mL}$ with the corresponding extraction solvents. Then the $50 \mathrm{~mL}$ diluted extraction solution was employed to determine the total polyphenol and flavonoid contents. For extracts with 75 wt. \% ethanol/water solvents, another $50 \mathrm{~mL}$ of diluted solution was concentrated and dried at $50^{\circ} \mathrm{C}$ to a constant weight in the vacuum-drying oven. The dried extracts were preserved at $-18^{\circ} \mathrm{C}$. Before detection of the antioxidant and tyrosinase inhibitory properties, the dried powders were redissolved with 75 wt. \% ethanol/ water solvents at different concentrations, which included: 5.0, 7.5, 10.0, 15.0, 20.0, 25.0, 30.0, and $40.0 \mathrm{mg} / \mathrm{mL}$. Water extracts of bee pollen were expressed as WEP. Extracts of bee pollen using 25, 50,75 , and 100 wt. \% ethanol/water solvents were expressed as 25\% EEP, 50\% EEP, 75\% EEP, and $100 \%$ EEP, respectively.

\section{Determination of total polyphenol contents}

Total polyphenol contents were assayed according to the Folin-Ciocalteau approach, using protocatechuic acid as the reference standard. Briefly, each extraction solution $(0.5 \mathrm{~mL})$ of bee pollen sample was mixed with $0.5 \mathrm{~mL}$ of the Folin-Ciocalteau reagent $(2 \mathrm{~N})$ for $5 \mathrm{~min}$. After the addition of $1.5 \mathrm{~mL}$ sodium carbonate solution $(0.2 \mathrm{~g} / \mathrm{mL})$, the mixture was 
incubated for $10 \mathrm{~min}$ at room temperature. Then, the absorbance at $765 \mathrm{~nm}$ was measured using the UV-2500/Ultraviolet visible spectrophotometer (Shimadzu Co., Ltd., Kyoto, Japan). Protocatechuic acid as the standard solution ( $0-5 \mu \mathrm{g} / \mathrm{mL})$ was used for constructing the calibration curve ( $Y=166.8 X+$ $\left.0.0037, R^{2}=0.9998\right)$. Total polyphenol content (TPC) was expressed as the milligram of protocatechuic acid equivalents per gram of pollen $\left(\mathrm{mg}^{\mathrm{PAE}} \mathrm{g}^{-1}\right)$.

\section{Determination of total flavonoid contents}

The colorimetric method was used to determine total flavonoid contents according to the previous study (Vichapong et al., 2010) with slight modifications. Briefly, the extracting solution mixture $(0.5 \mathrm{~mL})$ and sodium nitrite $(0.4 \mathrm{~mL}, 5 \%)$ were left standing at room temperature for $6 \mathrm{~min}$ and then aluminum nitrate $(0.4 \mathrm{~mL}, 10 \%)$ was added. After incubation for another $6 \mathrm{~min}$, sodium hydroxide (4 mL, 4\%) was added to the mixture and diluted with the corresponding extraction solvents to $10 \mathrm{~mL}$. After incubation for $15 \mathrm{~min}$ at room temperature, the absorbance was measured at $510 \mathrm{~nm}$ using UV-2500/Ultraviolet visible spectrophotometer (Shimadzu Co., Ltd., Kyoto, Japan). The total flavonoid content (TFC) was calculated from the calibration curve of rutin standard $(Y=11.796 X-$ $\left.0.0022, R^{2}=0.9994\right)$. The total flavonoid content was expressed as the milligram of rutin equivalent per gram of pollen ( $\mathrm{mg}$ RE $\mathrm{g}^{-1}$ ).

\section{Trolox equivalent antioxidant capacity (TEAC)}

The trolox equivalent antioxidant capacity (TEAC) of pollen extracts was determined with the ABTS radical cation (ABTS+-) decolourization assay developed by $\operatorname{Re}$ et al. (1999). The chemical compound ABTS, was dissolved in water to a final concentration of $0.7 \mathrm{mM}$. Next, we produced ABTS+. by reacting the ABTS stock solution $(5 \mathrm{~mL}, 0.7 \mathrm{mM})$ with potassium persulfate $(88 \mu \mathrm{L}, 140 \mathrm{mM})$ at room temperature for 16 - $17 \mathrm{~h}$ in the dark. Afterwards, ethanol was used to dilute the ABTS+- solution to an absorbance of $0.7 \pm 0.02$ at $734 \mathrm{~nm}$. All measurements were performed as follows: diluted ABTS+. $(2 \mathrm{~mL})$ was mixed with the corresponding concentration solutions ( $100 \mu \mathrm{L}, 5.0-40.0 \mathrm{mg} / \mathrm{mL})$. Then the mixture was stirred for $30 \mathrm{~s}$, and incubated for $6 \mathrm{~min}$ in the dark. The absorbance of the mixture was measured at $734 \mathrm{~nm}$ using $75 \mathrm{wt}$ \% ethanol/ water solvent as the blank. Trolox equivalent antioxidant capacity (TEAC) was expressed as millimole Trolox equivalents per gram pollen (mmol TE $\mathrm{g}^{-1}$ ).

\section{DPPH radical scavenging activity}

The method of Brand-Williams et al. (1995) with slight modification, was used to determine the DPPH radical scavenging activity of the pollen extracts. Firstly, $0.2 \mathrm{~mL}$ of various concentration solutions (5.0 - $40.0 \mathrm{mg} / \mathrm{mL}$ ) was mixed with $2 \mathrm{~mL}$ ethanol, $1.8 \mathrm{~mL}$ water, and $2 \mathrm{~mL}$ of DPPH solution $(0.2 \mathrm{mmol} / \mathrm{L})$. The mixture was rapidly shaken and then kept for 30 min at room temperature in the dark. Absorbance was measured at $517 \mathrm{~nm}$ (A517 nm) using UV-2500/ Ultraviolet visible spectrophotometer (Shimadzu Co., Ltd., Kyoto, Japan). The absorbance of the control was measured using a mixture of $1.8 \mathrm{~mL}$ water and $2 \mathrm{~mL}$ of DPPH solution. A calculation of the DPPH radical scavenging activity was done using the following formula:

$\%$ of DPPH radical scavenging activity $=1-\mathrm{OD}$ Sample / the OD Control

$50 \%$ radical scavenging activity $\left(\mathrm{IC}_{50}\right)$ was calculated from the graph of \% of DPPH radical scavenging activity against the extraction concentration.

\section{Determination of reducing power}

The reducing power of pollen extracts was determined according to the method of Duh (1998) with minor modifications. Redissolved extracting solution $(20 \mathrm{mg} / \mathrm{mL}, 0.2 \mathrm{~mL})$ was mixed with $2.5 \mathrm{~mL}$ phosphate-buffered saline (PBS) (2.0 M, pH 6.6) and $2.5 \mathrm{~mL}$ potassium ferricyanide (1.0\%). The mixture was incubated for $20 \mathrm{~min}$ at $50^{\circ} \mathrm{C}$. After $1.0 \mathrm{~mL}$ trichloroacetic acid (10\%) had been added to the mixture, the mixture was centrifuged at $2500 \times \mathrm{g}$ for $10 \mathrm{~min}$. Then, $2.5 \mathrm{~mL}$ supernatant was mixed with $2.5 \mathrm{~mL}$ distilled water and $0.5 \mathrm{~mL}$ of $0.1 \%$ ferric chloride. The absorbance of the final mixture was measured at $700 \mathrm{~nm}$ using the UV-2500/Ultraviolet visible spectrophotometer (Shimadzu Co., Ltd., Kyoto, Japan). The reducing power was calculated using the following formula: $\left(A_{0}-A_{1}\right) / A_{0}{ }^{*} 100$, in which $A_{0}$ is the absorbance of the control and $A_{1}$ is the absorbance of the pollen sample.

\section{Tyrosinase Inhibitory Activities}

The tyrosinase inhibitory activities of pollen extracts were measured according to the spectrophotometric method (Jo et al., 2012) with minor modifications. A redissolved extracting solution $(0.1 \mathrm{~mL}, 25 \mathrm{mg} / \mathrm{mL})$ was mixed with $1.8 \mathrm{~mL}$ PBS $(0.1 \mathrm{M}, \mathrm{pH} 6.8)$ and then added to $1 \mathrm{~mL}$ L-tyrosine or L-dopa (0.03\%). The mixture was incubated for $10 \mathrm{~min}$ at $37^{\circ} \mathrm{C}$. After the addition of $0.1 \mathrm{~mL}$ of tyrosinase solution (1000 $\mathrm{U} \mathrm{mL}^{-1}$ in PBS), the mixture was incubated for $5 \mathrm{~min}$ at $37^{\circ} \mathrm{C}$. The amount of dopachrome or 
melanins in the mixture was determined by optical density at $475 \mathrm{~nm}$ using the UV-2500/Ultraviolet visible spectrophotometer (Shimadzu Co., Ltd., Kyoto, Japan). As the positive standard of a monophenolase and diphenolase inhibitor, L-ascorbic acid and Kojic acid were used. The inhibitory percentage of tyrosinase was calculated as follows: \% inhibition $=\{(A-B)-(C-D)\} /(A-B)(A:$ OD at $475 \mathrm{~nm}$ without the test substance; $\mathrm{B}: \mathrm{OD}$ at $475 \mathrm{~nm}$ without the test substance and tyrosinase; C: OD at $475 \mathrm{~nm}$ with the test substance; D: OD at $475 \mathrm{~nm}$ with the test substance, but without tyrosinase). The dose inhibition curve was used to calculate the $\mathrm{IC}_{50}$ value.

\section{Statistical analysis}

The experimental results were expressed as the mean \pm SD of triplicate measurements. The data were subjected to ANOVA by using Duncan's multiple range test with SAS version 9.1 (SAS Institute Inc., Cary, NC, USA). For the purposes of this article, a p-value of $<0.05$ was considered statistically significant.

\section{RESULTS}

\section{Total polyphenol and flavonoid contents}

Bee pollen has been well characterised for its health benefits, especially for its antioxidant activities. Antioxidant activities of various species of monofloral bee pollen are mainly attributed to their polyphenols (Leblance et al., 2009). Fourteen species of monofloral bee pollen from China were extracted with different aqueous ethanol solutions. For this study, the TPC and TFC of bee pollen extracts were determined and expressed as milligram protocatechuic acid equivalents per gram of pollen (mg PAE ${ }^{-1}$ ) and milligram rutin equivalents per gram of pollen (mg RE g ${ }^{-1}$ ).

On Table 2 and 3, the great differences of TPC and TFC among various bee pollen extracts can be seen. It is shown that, 75\% EEP possessed the highest TPC and TFC, followed by $50 \%$ EEP; whereas, WEP had the lowest TPC and TFC. According to the highest TPC, the pollen sample could be divided into two groups. The first group was those extracts with higher TPC which varied from 12.90 to $22.41 \mathrm{mg} \mathrm{PAE} \mathrm{g}^{-1}$, including peach, wuweizi, phellodendron, apricot, dandelion, hawthorn, and rape pollen. The second group was those extracts with lower TPC between 1.81 and $8.38 \mathrm{mg} \mathrm{PAE} \mathrm{g}^{-1}$, involving such bee pollen as rose, chrysanthemum, camellia, sunflower, ageratum, buckwheat, and lotus. On the other hand, the TFC average in the first group was $17.21 \mathrm{mg} R E$ $\mathrm{g}^{-1}$; much greater than the average $7.47 \mathrm{mg} \mathrm{RE} \mathrm{g}^{-1}$ in the second group. According to the TPC and TFC of extracts, 75 wt. \% ethanol/water solvent may be the most effective solvent to extract phenolic compounds of various species of bee pollen. Consequently, the TPC and TFC extracts were used in subsequent antioxidant and tyrosinase inhibitory activity experiments.

Species, producing region, time of collection, purity, and colour of pollen sample

\begin{tabular}{cccccc}
\hline Scientific name & Common name & Producing region & $\begin{array}{c}\text { Time of } \\
\text { collection }\end{array}$ & $\begin{array}{c}\text { Purity } \\
\text { (\%) }\end{array}$ & Colour \\
\hline Agastache rugosatache rugosa & Ageratum & Yichun, Heilongjiang & July & $93.3 \%$ & Light yellow \\
\hline Brassica napus L. & Rape & Xining, Qinghai & July & $95.6 \%$ & Bright yellow \\
\hline Camellia japonica L. & Camellia & Kunming, Yunnan & March & $91.6 \%$ & Bright yellow \\
\hline Crataegus pinnatifida Bunge & Hawthorn & Xinxiang, Henan & April & $91.2 \%$ & Light yellow \\
\hline Dendranthema indicum L. & Chrysanthemum & Liuan,Anhui & October & $90.2 \%$ & Bright yellow \\
\hline Fagopyrum esculentum moench & Buckwheat & Datong, Shanxi & July & $94.8 \%$ & Dark yellow \\
\hline Helianthus annuus L. & Sunflower & Gannan, Heilongjiang & August & $94.6 \%$ & Orange yellow \\
\hline Nelumbo nucifera Gaertn. & Lotus & Enshi, Hubei & July & $93.8 \%$ & Light yellow \\
\hline Phellodendron amurensis & Phellodendron & Enshi, Hubei & June & $91.3 \%$ & Brown yellow \\
\hline Prunus armeniaca & Apricot & Xinhe, Hebei & March & $94.3 \%$ & Light green \\
\hline Prunus persica L. & Peach & Pinggu, Beijing & July & $92.7 \%$ & Brown yellow \\
\hline Rosa rugosa Thunb. & Rose & Pingyin, Shandong & May & $91.2 \%$ & Light yellow \\
\hline Schisandra chinensis & Wuweizi & Linhe, Neimenggu & May & $91.6 \%$ & Deep yellow \\
\hline Taraxacum mongolicum Hand & Dandelion & Yichun, Heilongjiang & June & $92.5 \%$ & Light yellow \\
\hline
\end{tabular}


Trolox equivalent antioxidant capacity (TEAC)

Trolox equivalent antioxidant capacity was investigated and expressed as millimole Trolox equivalents

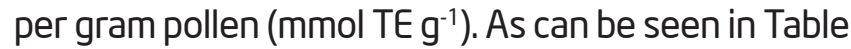
4 , the TEAC values of the bee pollen samples ranged

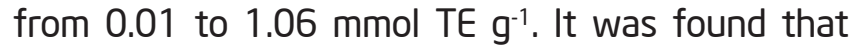
the TEAC values of bee pollen extracts in the first group were almost 1 - 2 orders of magnitude higher than those in the second group $(p<0.05)$. Extracts of wuweizi, phellodendron, dandelion, camellia, rape, and apricot pollen had the higher TEAC values; while, extracts of chrysanthemum, sunflower, ageratum, and lotus pollen exhibited lower TEAC values. All the samples had lower TEAC values than that of the control trolox, $4.01 \mathrm{mmol}^{\mathrm{TE} \mathrm{g}^{-1} \text {. }}$

\section{DPPH radical scavenging activity}

A measurement of the DPPH radical scavenging ability was done to evaluate the antioxidant activities of bee pollen extracts. The results were expressed as $I_{50}$. The lower $I_{50}$ value indicates stronger antioxidant ability.

The extracts' $I C_{50}$ varied depending on the floral species of the bee pollen. The range of the $\mathrm{IC}_{50}$ was from 1.28 to $127.57 \mathrm{mg} / \mathrm{mL}$ (Tab. 4). The first group's $\mathrm{IC}_{50}$ values of the extracts were lower than $10.00 \mathrm{mg} / \mathrm{mL}$, except hawthorn pollen which was $11.66 \mathrm{mg} / \mathrm{mL}$. In the second group, the $\mathrm{IC}_{50}$ values were almost higher than $10.00 \mathrm{mg} / \mathrm{mL}$, except for chrysanthemum and rose pollen, which were 9.05 and $6.94 \mathrm{mg} / \mathrm{mL}$. Among all the pollen samples, rape, wuweizi, and phellodendron pollen showed a stronger DPPH radical scavenging ability, followed by dandelion, rose, apricot, peach, buckwheat, and chrysanthemum pollen; whereas lotus pollen significantly demonstrated the weakest scavenging capacity of DPPH $(p<0.05)$.

\section{Reducing power}

The reducing power of the bee pollen extracts was investigated by measuring the $\mathrm{Fe}^{3+}$ to $\mathrm{Fe}^{2+}$ conversion. The results were expressed as the reducing power, and the higher value indicates the stronger antioxidant ability.

The mean value of the reducing power in the first group was 41.14; much higher than the 17.64 of the second group (Tab. 4). In group one, the reducing power values among five out of seven samples, presented more than 25.00 , while that of camellia pollen was the only one more than 25.00 in group two. Extracts of peach and wuweizi pollen significantly exhibited the highest reducing power, and in order - followed by: hawthorn and rape pollen> camellia pollen > phellodendron pollen $(p<0.05)$. Extracts of buckwheat and lotus pollen possessed much lower reducing power values.

Table 2.

Total phenolic contents of the ethanolic extracts of 14 pollen types

\begin{tabular}{|c|c|c|c|c|c|c|}
\hline \multirow{2}{*}{ No. } & \multirow{2}{*}{ Common name } & \multicolumn{5}{|c|}{ TPC (mg PAE g-1) } \\
\hline & & WEP & $25 \%$ EEP & $50 \%$ EEP & $75 \%$ EEP & 100\% EEP \\
\hline 1 & Rape & $5.39 \pm 0.05^{9,1}$ & $5.46 \pm 0.05^{\mathrm{i}, 1}$ & $10.68 \pm 0.92^{f, 3}$ & $12.90 \pm 1.17^{f, 4}$ & $9.28 \pm 0.63^{e, 2}$ \\
\hline 2 & Wuweizi & $7.13 \pm 0.28^{\mathrm{d}, 1}$ & $8.04 \pm 0.72^{\mathrm{f}, 2}$ & $19.22 \pm 0.35^{a, 4}$ & $21.04 \pm 0.57^{b, 5}$ & $12.78 \pm 0.11^{c, 3}$ \\
\hline 3 & Phellodendron & $11.53 \pm 0.61^{c, 1}$ & $11.96 \pm 0.80^{d, 1}$ & $17.32 \pm 0.45^{\mathrm{b}, 3}$ & $19.15 \pm 0.07^{c, 4}$ & $14.60 \pm 0.57^{\mathrm{b}, 2}$ \\
\hline 4 & Apricot & $11.76 \pm 0.98^{c, 2}$ & $13.70 \pm 0.17^{c, 3}$ & $15.28 \pm 0.03^{c, 4}$ & $17.73 \pm 0.71^{d, 5}$ & $9.71 \pm 0.56^{e, 1}$ \\
\hline 5 & Dandelion & $6.41 \pm 0.25 \mathrm{e}^{\mathrm{f}, 1}$ & $10.03 \pm 0.21^{e, 2}$ & $13.87 \pm 0.33^{\mathrm{d}, 4}$ & $15.52 \pm 0.1^{e, 5}$ & $10.95 \pm 0.31^{d, 3}$ \\
\hline 6 & Hawthorn & $5.81 \pm 0.05^{\mathrm{fg}, 1}$ & $6.72 \pm 0.049,2$ & $11.04 \pm 0.25^{e, 3}$ & $15.72 \pm 0.01^{e, 5}$ & $12.42 \pm 0.05^{c, 4}$ \\
\hline 7 & Peach & $23.51 \pm 0.05^{a, 3}$ & $23.57 \pm 0.90^{a, 3}$ & $18.92 \pm 0.97^{\mathrm{a} b, 2}$ & $22.41 \pm 1.42^{\mathrm{a}, 3}$ & $15.48 \pm 0.21^{a, 1}$ \\
\hline 8 & Buckwheat & $3.33 \pm 0.08^{\mathrm{i}, 1}$ & $3.39 \pm 0.13^{\mathrm{j}, 1}$ & $4.70 \pm 0.14^{i, 3}$ & $5.48 \pm 0.02^{\mathrm{j}, 4}$ & $4.35 \pm 0.01^{\mathrm{h}, 2}$ \\
\hline 9 & Chrysanthemum & $5.69 \pm 0.22^{9,1}$ & $5.65 \pm 0.32 \mathrm{~h}^{\mathrm{i}, 1}$ & $6.56 \pm 0.26^{h, 2}$ & $7.83 \pm 0.09^{h, 3}$ & $5.94 \pm 0.11^{\mathrm{fg}, 1}$ \\
\hline 10 & Sunflower & $3.34 \pm 0.08^{\mathrm{i} 1}$ & $4.01 \pm 0.31^{\mathrm{j}, 2}$ & $6.35 \pm 0.03^{h, 4}$ & $6.65 \pm 0.15^{i, 4}$ & $5.88 \pm 0.33^{\mathrm{fg}, 3}$ \\
\hline 11 & Ageratum & $6.78 \pm 0.11 d^{e, 4}$ & $6.44 \pm 0.10^{g h, 3}$ & $6.30 \pm 0.00^{h, 23}$ & $6.14 \pm 0.06^{\mathrm{i}, 2}$ & $2.45 \pm 0.05^{\mathrm{i}, 1}$ \\
\hline 12 & Camellia & $4.07 \pm 0.02^{\mathrm{h}, 1}$ & $4.15 \pm 0.45^{\mathrm{j}, 1}$ & $6.66 \pm 0.31^{h, 3}$ & $6.98 \pm 0.08^{\mathrm{hi}, 3}$ & $5.48 \pm 0.32^{g, 2}$ \\
\hline 13 & Rose & $5.08 \pm 0.15^{9,1}$ & $5.26 \pm 0.26^{i, 12}$ & $7.62 \pm 0.02^{g, 3}$ & $8.38 \pm 0.13^{9,4}$ & $5.58 \pm 0.19^{92}$ \\
\hline 14 & Lotus & $3.13 \pm 0.03^{i, 3}$ & $2.07 \pm 0.03^{\mathrm{k}, 2}$ & $1.73 \pm 0.02^{\mathrm{j}, 1}$ & $1.81 \pm 0.16^{\mathrm{k}, 1}$ & $1.78 \pm 0.25^{j 1,5}$ \\
\hline
\end{tabular}

Note: Data are mean \pm SD $(n=3)$. Total polyphenol contents (TPC) were expressed as milligram protocatechuic acid equivalents per gram pollen (mg PAE $\mathrm{g}^{-1}$ ). Columns within a sample sharing the same letter are not significantly different by Duncan's range test $(p<0.05)$. Rows within a sample sharing the same number are not significantly different by Duncan's range test $(p<0.05)$. Water extracts of bee pollen were expressed as WEP. Extracts of bee pollen by using 25, 50, 75 and $100 \mathrm{wt}$. \% ethanol/water solvents were expressed as 25\% EEP, 50\% EEP, 75\% EEP and 100\% EEP, respectively. 
Table 3.

Total flavonoid contents of the ethanolic extracts of 14 pollen types

\begin{tabular}{|c|c|c|c|c|c|c|}
\hline \multirow{2}{*}{ No. } & \multirow{2}{*}{ Common name } & \multicolumn{5}{|c|}{ TFC (mg RE $\left.\mathrm{g}^{-1}\right)$} \\
\hline & & WEP & $25 \%$ EEP & $50 \%$ EEP & $75 \%$ EEP & 100\% EEP \\
\hline 1 & Rape & $0.33 \pm 0.00^{\mathrm{gh}, 1}$ & $3.57 \pm 0.15^{e, 2}$ & $11.93 \pm 0.12^{\mathrm{b}, 3}$ & $24.00 \pm 0.17^{a, 5}$ & $20.73 \pm 0.43^{\mathrm{a}, 4}$ \\
\hline 2 & Wuweizi & $0.65 \pm 0.00^{f, 1}$ & $3.69 \pm 0.04^{e, 2}$ & $10.59 \pm 0.34^{c, 3}$ & $18.93 \pm 0.86^{\mathrm{b}, 5}$ & $16.05 \pm 0.24^{b, 4}$ \\
\hline 3 & Phellodendron & $3.33 \pm 0.01^{b, 1}$ & $6.92 \pm 0.18^{b, 2}$ & $14.40 \pm 0.47^{a, 4}$ & $18.78 \pm 0.63^{b, 5}$ & $9.57 \pm 0.06^{\mathrm{fg}, 3}$ \\
\hline 4 & Apricot & $2.79 \pm 0.72^{c, 1}$ & $6.01 \pm 0.23^{c, 2}$ & $8.21 \pm 0.38^{e, 3}$ & $15.54 \pm 0.77^{c, 5}$ & $10.47 \pm 0.12^{\mathrm{de}, 4}$ \\
\hline 5 & Dandelion & $3.73 \pm 0.11^{a, 1}$ & $7.51 \pm 0.20^{\mathrm{a}, 2}$ & $10.62 \pm 0.48^{c, 3}$ & $15.43 \pm 0.23^{c, 5}$ & $11.88 \pm 0.18^{\mathrm{d}, 4}$ \\
\hline 6 & Hawthorn & $0.94 \pm 0.06^{e, 1}$ & $1.76 \pm 0.03^{h, 2}$ & $5.55 \pm 0.95^{9,3}$ & $13.92 \pm 1.14^{\mathrm{d}, 5}$ & $6.87 \pm 0.19^{\mathrm{i}, 4}$ \\
\hline 7 & Peach & $2.62 \pm 0.08^{c, 1}$ & $4.65 \pm 0.13^{\mathrm{d}, 2}$ & $9.00 \pm 0.23^{d, 3}$ & $13.89 \pm 0.28^{d, 5}$ & $13.26 \pm 0.15^{c, 4}$ \\
\hline 8 & Buckwheat & $0.41 \pm 0.03^{g, 1}$ & $2.41 \pm 0.20^{f, 2}$ & $6.21 \pm 0.05^{f, 3}$ & $13.23 \pm 0.12^{d, 5}$ & $9.05 \pm 0.11^{9,4}$ \\
\hline 9 & Chrysanthemum & $1.25 \pm 0.02^{\mathrm{d}, 1}$ & $2.19 \pm 0.01^{9,2}$ & $5.63 \pm 0.43^{9,3}$ & $12.09 \pm 0.02^{e, 5}$ & $9.74 \pm 0.25^{f, 4}$ \\
\hline 10 & Sunflower & $0.40 \pm 0.03^{g h, 1}$ & $2.18 \pm 0.04^{9,2}$ & $4.34 \pm 0.41^{\mathrm{h}, 3}$ & $10.34 \pm 0.01^{\mathrm{f}, 5}$ & $7.78 \pm 0.37^{h, 4}$ \\
\hline 11 & Ageratum & $0.71 \pm 0.03^{\mathrm{ef}, 1}$ & $1.78 \pm 0.02^{h, 2}$ & $3.67 \pm 0.10^{i, 3}$ & $8.73 \pm 0.20^{9,5}$ & $7.84 \pm 0.1424^{\mathrm{h}, 4}$ \\
\hline 12 & Camellia & $0.93 \pm 0.03^{e, 1}$ & $1.11 \pm 0.08^{\mathrm{i}, 1}$ & $2.10 \pm 0.08^{\mathrm{j}, 2}$ & $5.96 \pm 0.09^{\mathrm{h}, 4}$ & $3.18 \pm 0.20^{j, 3}$ \\
\hline 13 & Rose & $0.74 \pm 0.01^{e f, 1}$ & $0.80 \pm 0.02^{\mathrm{j}, 2}$ & $0.81 \pm 0.02^{k, 2}$ & $1.02 \pm 0.01^{i, 3}$ & $0.73 \pm 0.03^{k, 1}$ \\
\hline 14 & Lotus & $0.16 \pm 0.00^{h, 1}$ & $0.28 \pm 0.01^{k, 2}$ & $0.32 \pm 0.02^{1,2}$ & $0.90 \pm 0.01^{i, 4}$ & $0.38 \pm 0.05^{k, 3}$ \\
\hline
\end{tabular}

Note: Data are the mean \pm SD $(n=3)$. Total flavonoids contents (TFC) were expressed as milligram rutin equivalents рег gram pollen (mg RE $\mathrm{g}^{-1}$ ). Columns within a sample sharing the same letter are not significantly different using Duncan's range test $(p<0.05)$. Rows within a sample sharing the same number are not significantly different using Duncan's range test $(p<0.05)$. Water extracts of bee pollen were expressed as WEP. Extracts of bee pollen by using $25,50,75$, and 100 wt. \% ethanol/water solvents were expressed as 25\% EEP, 50\% EEP, 75\% EEP, and 100\% EEP, respectively.

Table 4.

Antioxidant and tyrosinase inhibitory activities of 14 types of pollen

\begin{tabular}{|c|c|c|c|c|c|c|}
\hline \multirow[t]{2}{*}{ No. } & \multirow[t]{2}{*}{ Common name } & \multirow{2}{*}{$\begin{array}{c}\text { TEAC } \\
\left(\mathrm{mmol} \mathrm{TE} \mathrm{g}^{-1}\right)\end{array}$} & \multirow{2}{*}{$\begin{array}{c}\text { DPPH } \\
I_{50}(\mathrm{mg} / \mathrm{mL})\end{array}$} & \multirow{2}{*}{$\begin{array}{l}\text { Reducing } \\
\text { power }\end{array}$} & \multicolumn{2}{|c|}{$\begin{array}{l}\text { Tyrosinase inhibitory } \\
\text { activity } \mathrm{IC}_{50}(\mathrm{mg} / \mathrm{mL})\end{array}$} \\
\hline & & & & & Monophenolase & Dipheno \\
\hline 1 & Rape & $21 \pm$ & $1.28 \pm 0.03^{\mathrm{a}}$ & $2.63^{9}$ & $2.28 \pm 0.04^{9}$ & \\
\hline 2 & (1) & $1.06 \pm 0.02^{k}$ & $1.66 \pm 0.03^{a}$ & $68.17 \pm 0.59^{h}$ & $32 \pm 0$ & $\pm 0.04^{c}$ \\
\hline 3 & Phellodendrc & $41 \pm 0.0$ & $2.50 \pm 0$ & $25.27 \pm 0.003^{d}$ & $0.61 \pm 0$ & $\pm 0.03^{d}$ \\
\hline 4 & 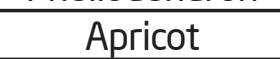 & $\mathrm{2}^{\mathrm{e}}$ & $9.70 \pm$ & & $12 \pm$ & \\
\hline 5 & & $7^{\mathrm{h}}$ & 4.34 & & $0.60 \pm$ & $0.04^{c}$ \\
\hline 6 & 2 & $d$ & $11.66 \pm$ & 46.34 & $0.36 \pm$ & $\pm 0.06^{\mathrm{gh}}$ \\
\hline 7 & each & $1^{d}$ & $9.92 \pm$ & 70.55 & $0.40 \pm$ & $\pm 0.08^{\mathrm{fg}}$ \\
\hline 8 & $\mathrm{ckv}$ & $5 \pm 0$ & 10.16 & $14.17 \pm$ & $2.66 \pm$ & $\pm 0.01^{\mathrm{b}}$ \\
\hline 9 & ant & $04 \pm 0$. & $9.05 \pm 0.51^{d}$ & $9.38 \pm 0.09^{a}$ & $0.58 \pm 0$ & $\pm 0.02^{\mathrm{ef}}$ \\
\hline 10 & fflo & $04 \pm 0$ & $20.46 \pm 0$ & $17.38 \pm 1.47^{c}$ & $0.47 \pm 0$ & $\pm 0.00^{\mathrm{a}}$ \\
\hline 11 & Agera & $4 \pm 0.00^{b}$ & $45.16 \pm 0.21^{9}$ & $16.20 \pm 0.29^{c}$ & $0.90 \pm 0.02^{\dagger}$ & $\pm 0.00^{c}$ \\
\hline 12 & Camellia & $0.22 \pm 0.02^{\mathrm{fg}}$ & $11.52 \pm 0.25^{\mathrm{e}}$ & $37.73 \pm 2.32^{f}$ & $0.21 \pm 0.02^{\mathrm{a}}$ & $0 \pm 0.00^{b}$ \\
\hline 13 & Rose & $0.08 \pm 0.00^{c}$ & $6.94 \pm 0.12^{c}$ & $16.16 \pm 0.56^{c}$ & $0.38 \pm 0.02^{b}$ & $9 \pm 0.02^{e}$ \\
\hline 14 & Lotus & $0.01 \pm 0.00^{a}$ & $127.57 \pm 1.37^{h}$ & $12.43 \pm 0.19^{a b}$ & $2.41 \pm 0.16^{h}$ & $0.39 \pm 0.01^{b}$ \\
\hline
\end{tabular}

Note: Data are the mean \pm SD $(n=3)$. The means with different superscript letters within a column are significantly different at $p<0.05$ using Duncan's range test. Trolox equivalent antioxidant capacity (TEAC) was expressed as millimole Trolox equivalents per gram pollen (mmol TE $\left.\mathrm{g}^{-1}\right)$. The DPPH (1,1-diphenyl-2-picrylhydrazyl) radical scavenging activity was expressed as the $50 \%$ radical scavenging activity $\left(\mathrm{IC}_{50}\right)$. 


\section{J. APPC. SCL. VOL. 59 N NO. 12015}

\section{Tyrosinase inhibitory activity}

Inhibitory activities of bee pollen extracts on tyrosinase activities were investigated by using L-tyrosine and L-DOPA separately, as the substrates. The results are expressed as $I_{C_{50}}$. A lower $I_{50}$ value indicates a stronger inhibitory ability. When L-tyrosine was used as a substrate, extracts of apricot $\left(\mathrm{IC}_{50}=0.12 \mathrm{mg} / \mathrm{mL}\right)$ and camellia $\left(I C_{50}=0.21 \mathrm{mg} / \mathrm{mL}\right)$ pollen revealed the strongest inhibitory activity against tyrosinase (Tab. 4). Extracts of apricot, camellia, hawthorn, peach, rose, sunflower, chrysanthemum, phellodendron, dandelion, wuweizi, and ageratum pollen had $\mathrm{IC}_{50}$ values which were significantly lower than that of L-ascorbic acid $\left(I_{50}=1.45 \mathrm{mg} / \mathrm{mL}, \quad P<0.05\right)$; a well-known monophenolase inhibitor against tyrosinase (Sezer et al., 2014). In contrast, extracts of rape, lotus, and buckwheat pollen demonstrated much weaker inhibitory activity than L-ascorbic acid $\left(\mathrm{IC}_{50}=1.45 \mathrm{mg} / \mathrm{mL}\right)$.

On the other hand, when L-DOPA was used as a substrate, extracts of sunflower $\left(I_{5_{0}}=0.30 \mathrm{mg} / \mathrm{mL}\right)$, apricot $\left(I C_{50}=0.38 \mathrm{mg} / \mathrm{mL}\right)$, lotus $\left(I C_{50}=0.39 \mathrm{mg} / \mathrm{mL}\right)$, buckwheat $\left(\mathrm{IC}_{50}=0.40 \mathrm{mg} / \mathrm{mL}\right)$, and camellia $\left(\mathrm{IC}_{50}=0.40 \mathrm{mg} / \mathrm{mL}\right)$ pollen presented the stronger inhibitory activity $(p<0.05)$. Apart from extracts of hawthorn and rape pollen, extracts of other bee pollen exhibited much stronger inhibitory activity than kojic acid $\left(I C_{50}=1.31 \mathrm{mg} / \mathrm{mL}\right)$; a well-known diphenolase inhibitor against tyrosinase (Noh et al., 2009).

\section{DISCUSSION}

Bee pollen is a natural source of nutrients and phytochemical compounds, especially polyphenols. These compounds are considered beneficial for human health due to their wide range of biological activities, including antimicrobial, anticarcinogenic, antioxidant activity, and skin whitening (Kubo et al., 2000; Wu et al., 2003; Ulusoy and Kolayli, 2014). The phenolic profiles from plant materials mainly depend on the plant origins and extraction solvents. Our previous work explored the phenolic contents and antioxidant activities of six types of monofloral bee pollen extracted only with 80 wt. \% ethanol/water solvent (Zhang et al., 2007). To choose a solvent that was good enough for polyphenol extraction and safe enough for humans, we used various aqueous ethanol solvents to extract polyphenol from 14 species of monofloral bee pollen in China. We also evaluated the antioxidant and tyrosinase inhibitory properties of these extracts.
Our results suggest that the polyphenol and flavonoid contents of bee pollen samples very significantly varied according to the floral species (Tab. 2 and 3). These results were in agreement with a previous study which reported that the TPC of six types of bee pollen from the Sonoran desert were clearly different from each other (Leblance et al., 2009). On the other hand, the extraction solvent was another crucial factor influencing the polyphenol and flavonoid contents of bee pollen extracts. When compared with our previous work (Zhang et al., 2007), our results indicated that the TPC and TFC of extracts using 75 wt. \% ethanol/water solvent presented the highest amount among all the species, compared with those of extracts using other aqueous ethanol solvents (Tab. 2 and 3). A similar conclusion, that both TPC and TFC of $70 \mathrm{wt}$. \% ethanol/water extract of peony pollen were higher than those of 30 wt. $\%$ and 100 wt. \% ethanol/water extracts, was found (Huang et al., 2012). Additionally, the maximum amount of polyphenol was also obtained from Morinda citrifolia and Cynara scolymus by using 75 wt. \% ethanol/water solvent (Vamanu et al., 2011; Thoo et al., 2013). This higher TPC or TFC, may be ascribed to the fact that ethanol can effectively increase the permeability of the cell wall, and water can cause further solubility of polar substances in the cell (Saenkod et al., 2013). Thus, $75 \mathrm{wt}$. \% ethanol/water solvent seems to facilitate efficient extraction of polar substances and may be the most optimal binary solvent for extracting polyphenols from bee pollen.

The antioxidant activities of bee pollen extracts were significantly different $(p<0.05)$, and mainly attributed to the floral species of the bee pollen (Tab. 4). The difference expressed for the in vitro assay is based on the abilities to scavenge free radicals (DPPH, ABTS) and reducing power. The extracts of wuweizi, phellodendron, rape, dandelion, and apricot pollen demonstrated higher antioxidant activities. Our results were identical to the previous studies - that rape pollen was found to have stronger antioxidant properties than sunflower pollen (FatrcováŠramková et al., 2013) and extracts of buckwheat and lotus pollen showed the lowest reducing power among 21 types of bee pollen sample (Tang et al., 2008). In addition, Cheng et al. (2013) verified that the strong antioxidant activities and the hepatoprotective effect of wuweizi pollen may be related to its free radical scavenging effect. It is well-known that wuweizi, dandelion, and phellodendron are used as traditional Chinese medicines. Wuweizi pulp extracts demonstrated high scavenging activities 
against DPPH radicals (Wu et al., 2011). Dandelion flower extracts containing flavonoids and coumaric derivatives possessed marked antioxidant activities (Hu and Kitts, 2005). In addition, leaf extracts of phellodendron, demonstrated significant radical scavenging activity comparable to vitamin $E$ (Leu et al., 2006). Thus, we can speculate that bee pollen from plants used in traditional Chinese medicine would be good resources for the development of health care products.

Tyrosinase inhibitory activities showed notable variations among the bee pollen extracts $(p<0.05)$ (Tab. 4). Apricot, sunflower, and camellia pollen presented the strongest inhibitory activities against both monophenolase and diphenolase, and their $\mathrm{IC}_{50}$ values were lower than those of the positive standards. In contrast, only rape pollen showed the weakest inhibitory activities against both monophenolase and diphenolase. The results revealed that almost all bee pollen can strongly restrain the hydroxylation of a monophenol (monophenolase activity) and converse an o-diphenol to the corresponding o-quinone (diphenolase activity), thus preventing the formation of melanins. This appears to verify that almost all bee pollens have the ability to whiten skin. As mentioned above, some companies in China recommend that customers use camellia, sunflower, and lotus pollen for whitening. Our results seem to confirm that camellia and sunflower pollen can possess the strongest tyrosinase inhibitory activities, in other words, present the strongest whitening effect. The lotus pollen extracts showed a stronger inhibition against diphenolase and a weaker inhibition against monophenolase than the positive standards. Moreover, our results revealed that the tyrosinase inhibitory activities of apricot pollen were the same level as those of the camellia and sunflower pollen $(p<0.05)$. Unfortunately, the previous research was lacking information on apricot pollen; thus, we speculated that apricot pollen may also be used in skin-whitening cosmetics.

\section{CONCLUSIONS}

Our studies indicate that polyphenol contents of bee pollen extracts are mainly dependent on the floral species and extraction solvents. Almost all of the pollen extracts showed powerful antioxidant or strong tyrosinase inhibitory activities. We probably discovered that apricot pollen reveals excellent antioxidant as well as tyrosinase inhibitory activities. Overall, our study seems to provide evidence that bee pollen can be developed into natural health products because of its capacities for scavenging free radicals and inhibiting tyrosinase.

\section{ACKNOWLEDGMENT}

This research was supported by a grant project of the Agricultural Science and Technology Innovation Program (CAAS-ASTIP-2015-IAR), from the Ministry of Agriculture of the P.R. China.

\section{REFERENCES}

Brand-Williams W., Cuvelier M. E., Berset C. (1995) Use of a free radical method to evaluate antioxidant activity. LWT-Food Science and Technology 28(1): 25-30,

Cheng N., Ren N., Gao H., Lei X., Zheng J., Cao W. (2013) Antioxidant and hepatoprotective effects of Schisandra chinensis pollen extract on CCl4-induced acute liver damage in mice. Food and Chemical Toxicology 55: 234-240.

Duh P. D. (1998) Antioxidant activity of burdock (Arctium lappa Linne): its scavenging effect on free-radical and active oxygen. Journal of the American Oil Chemists' Society 75(4): 455-461

Fatrcová-Šramková K., Nozkova !., Kacaniova M., Mariassyova M., Rovna K., Stricik M. (2013) Antioxidant and antimicrobial properties of monofloral bee pollen. Journal of Environmental Science and Health Part B 48(2): 133138

Hu C., Kitts D. D. (2005) Dandelion (Taraxacum officinale) flower extract suppresses both reactive oxygen species and nitric oxide and prevents lipid oxidation in vitro. Phytomedicine 12(8): 588-597.

Huang H., Zhang Y., Zhang D., Feng M., An M. (2012) Study on Antioxidant Capacity of Peony Pollen Extracts (in Chinese with English abstract). Journal of Henan Agricultural Sciences 41(11): 117-120.

Huang H. C., Huang W. Y., Tsai T. C., Hsieh W. Y., Ko W. P." Chang K. J., Chang T. M. (2014) Supercritical fluid extract of Lycium chinense Miller root inhibition of melanin production and its potential mechanisms of action. BMC Complementary and Alternative Medicine 14(1): 208.

Jaiswal A. K., Rajauria G., Abu-Ghannam N., Guptua S. (2012) Effect of different solvents on polyphenolic content, antioxidant capacity and antibacterial activity of Irish York cabbage. Journal of Food Biochemistry 36(3): 344-358. 


\section{J. APCL. SCLI. VOL. 59 NO. 12015}

Jayanthi P., Lalitha P. (2014) Formulation development and assessment of skin whitening efficiency of ethyl acetate extract of Eichhornia crassipes (Mart.) solms by in vitro tyrosinase activity. International Journal of ChemTech Research 6(1): 178-182.

Jo Y. H., Seo G. U., Yuk H. G., Lee S. C. (2012) Antioxidant and tyrosinase inhibitory activities of methanol extracts from Magnolia denudata and Magnolia denudata var. purpurascens flowers. Food Research International 47(2): 197-200.

Kubo I., Kinst-Hori I., Chaudhuri S. K., Kubo Y., Sanchez Y., Ogura T. (2000) Flavonols from Heterotheca inuloides: Tyrosinase Inhibitory Activity and Structural Criteria. Bioorganic and Medicinal Chemistry 8(7): 1749-1755.

Leblance B W., Davis O K., Boue S., Delucca A., Deeby T. (2009) Antioxidant activity of Sonoran Desert bee pollen. Food Chemistry, 1 15(4), 1299-1305.

Leja M., Mareczek A., Wyzgolik G., Klepacz-Baniak J., Czekonska K. (2007) Antioxiditive properties of bee pollen in selected plant species. Food Chemistry 100: 237-240.

Leu C. H., Li C. Y., Yao X., Wu T. S. (2006) Constituents from the leaves of Phellodendron amurense and their antioxidant activity. Chemical and Pharmaceutical Bulletin 54(9): 1308-1311.

Li C. Y., Wu T. S. (2002) Constituents of the pollen of Crocus sativus $L$. and their tyrosinase inhibitory activity. Chemical and Pharmaceutical Bulletin 50(10): 13051309.

Noh J. M., Kwak S. Y., Seo H. S., Seo J. H., Kim B. G., Lee Y. S. (2009) Kojic acid-amino acid conjugates as tyrosinase inhibitors. Bioorganic and Medicinal Chemistry Letters 19(19): 5586-5589.

Pascoal A., Rodrigues S., Teixeira A., Feas X., Estevinho L. M. (2014) Biological activities of commerical bee pollens.: Antimicrobial, antimutagenic, antioxidant and anti-inflammatory. Food and Chemical Toxicology 63: 233-239.

Re R., Pellegrini N., Proteggente A., Pannala A., Yang M., Rice-Evans C. (1999) Antioxidant activity applying an improved ABTS radical cation decolorization assay. Free Radical Biology and Medicine 26(9): 1231-1237.

Saenkod C., Liu Z., Huang J., Gong Y. (2013) Anti-oxidative biochemical properties of extracts from some Chinese and Thai rice varieties. African Journal of Food Science 7(9): 300-305.

SAS version 9.1 (2003) SAS Institute Inc. Cary, NC, USA.

Sezer Senol F., Tareq Hassan Khan M., Orhan G., Gurkas E., Erdogan Orhan I., Subutay Oztekin N., Ak F. (2014) In Silico Approach to Inhibition of Tyrosinase by Ascorbic Acid Using Molecular Docking Simulations. Current Topics in Medicinal Chemistry 14(12): 1469-1472.

Sun G. Y. (1993) The atlas on pollen of honey plant in China (in Chinese). Science and Technology Publishing House. Tianjing. 74 pp.

Tang L., Li Q., Zhai J. L., Song Z. G. (2008) Comparative Study on the Antioxidant Capacity of Water Extract from 21 kinds of Bee Pollen (in Chinese with English abstract). Journal of Chinese Institute of Food Science and Technology 8(1): 17-21.

Thoo Y. Y., Ho S. K., Abas F., Lai O. M., Ho C. W., Tan C. P. (2013) Optimal Binary Solvent Extraction System for Phenolic Antioxidants from Mengkudu (Morinda citrifolia) Fruit. Molecules 18(6): 7004-7022.

Tsong-Min C. (2012) Tyrosinase and Tyrosinase Inhibitors. Journal of Biocatalysis and Biotransformation 1(2): $1-2$.

Ulusoy E., Kolayli S. (2014) Phenolic Composition and Antioxidant Properties of Anzer Bee Pollen. Journal of Food Biochemistry 38(1): 73-82.

Vamanu E., Vamanu A., Nita S., Colceriu S. (201 1) Antioxidant and antimicrobial activities of ethanol extracts of Cynara scolymus (Cynarae folium, Asteraceae Family). Tropical Journal of Pharmaceutical Research 10(6): 777-783.

Vichapong J., Sookserm M., Srijesdaruk V., Swatsitang P., Srijaranai S. (2010) High performance liquid chromatographic analysis of phenolic compounds and their antioxidant activities in rice varieties. LWT-Food Science and Technology 43(9): 1325-1330.

Wu L. C., Chen Y. C., Ho J. A. A., Yang C. S. (2003) Inhibitory effect of red koji extracts on mushroom tyrosinase. Journal of Agricultural and Food Chemistry 51 (15): 4240-4246. 
Wu X., Yu X., ling H. (201 1) Optimization of phenolic anti- Z Zhang H. C., Dong J., Li H., Li C. Y. (2007) Antioxidant acoxidant extraction from Wuweizi (Schisandra chinensis) tivities and contents of total polyphenols and flavonoids pulp using random-centroid optimazation methodol- in six kinds of bee pollens (in Chinese with English abogy. International journal of molecular sciences 12(9): stract). Food Science 28(9): 500-504. 6255-6266. 